\title{
Open and endovascular treatment of spinal dural arteriovenous fistulas: a 10-year experience
}

\author{
*Matthew J. Koch, MD, ${ }^{1}$ Christopher J. Stapleton, MD,' Pankaj K. Agarwalla, MD,1 \\ Collin Torok, MD, ${ }^{2}$ John H. Shin, MD, ${ }^{1}$ Jean-Valery Coumans, MD, ${ }^{1}$ Lawrence F. Borges, MD, ${ }^{1}$ \\ Christopher S. Ogilvy, MD, ${ }^{3}$ James D. Rabinov, MD, ${ }^{2}$ and Aman B. Patel, MD ${ }^{1,2}$
}

Departments of ${ }^{1}$ Neurosurgery and ${ }^{2}$ Radiology, Massachusetts General Hospital and Harvard Medical School; and ${ }^{3}$ Division of Neurosurgery, Beth Israel Deaconess Medical Center and Harvard Medical School, Boston, Massachusetts

OBJECTIVE Vascular malformations of the spine represent rare clinical entities with profound neurological implications. Previously reported studies on management strategies for spinal dural arteriovenous fistulas (sDAVFs) appeared before the advent of modern liquid embolic agents. Authors of the present study review their institutional experience with endovascularly and surgically treated sDAVFs.

METHODS The authors performed a retrospective, observational, single-center case series on sDAVFs treated with endovascular embolization, microsurgical occlusion, or both between 2004 and 2013. The mode, efficacy, and clinical effect of treatment were evaluated.

RESULTS Forty-seven patients with spinal arteriovenous malformations were evaluated using spinal angiography, which demonstrated 34 Type I sDAVFs (thoracic 20, lumbar 12, and cervical 2). Twenty-nine of the patients (85\%) were male, and the median patient age was 63.3 years. Twenty patients underwent primary endovascular embolization (16 Onyx, $4 \mathrm{~N}$-butyl cyanoacrylate [NBCA]), and 14 underwent primary surgical clipping. At a mean follow-up of 36 weeks, according to angiography or MR angiography, 5 patients treated with endovascular embolization demonstrated persistent arteriovenous shunting, whereas none of the surgically treated patients showed lesion persistence $(p=0.0237)$. Thirty patients (88\%) experienced some resolution of their presenting symptoms (embolization 17 [85\%], surgery 13 [93\%], $p=$ 1.00).

CONCLUSIONS Microsurgical occlusion remains the most definitive treatment modality for sDAVFs, though modern endovascular techniques remain a viable option for the initial treatment of anatomically amenable lesions. Treatment of these lesions usually results in some clinical improvement.

https://thejns.org/doi/abs/10.3171/2016.9.SPINE16394

KEY WORDS spinal dural arteriovenous fistula; endovascular; vascular disorders

$\mathrm{V}$ ASCULAR malformations of the spinal cord represent a rare clinical entity with profound clinical implications. ${ }^{79}$ Of these infrequent lesions, spinal dural arteriovenous fistulas (sDAVFs) are the most common. Fortunately, our understanding of the pathological anatomy allows a multifaceted approach to diagnosis and treatment. Fistula formation between a radicular artery and medullary vein leads to venous hypertension resulting in myelopathy. ${ }^{6}$ Management of these fistulas once relied on endovascular techniques solely for diagnosis and open surgery exclusively for treatment, but the lesions are now amenable to endovascular intervention given the emergence of liquid embolic agents. ${ }^{4,9,17}$ Studies in the late 1990s and early 2000 s called into question the role of endovascular embolization with liquid embolics because of the procedure's perceived inferiority to surgery. ${ }^{7,17}$ However, with the advent of more advanced endovascular techniques and liquid embolic agents, further evaluation of the role of endovascular embolization for adjuvant as well as definitive treatment of sDAVF is warranted. We present a series of patients with sDAVFs treated with endovascular, open, and multimodal therapies to more fully understand the optimal approach for managing these lesions.

\section{Methods}

We performed a retrospective, observational, singlecenter case series evaluating initial occlusion, recanaliza-

ABBREVIATIONS ASA = anterior spinal artery; $A V M=$ arteriovenous malformation; $D S A=$ digital subtraction angiography; $M R A=M R$ angiography; NBCA = N-butyl cyanoacrylate; sDAVF = spinal dural arteriovenous fistula.

SUBMITTED April 5, 2016. ACCEPTED September 19, 2016.

INCLUDE WHEN CITING Published online January 20, 2017; DOI: 10.3171/2016.9.SPINE16394.

* Drs. Rabinov and Patel share senior authorship of this work. 
tion, retreatment, and neurological status of patients with sDAVFs who had undergone embolization and/or resection. After obtaining institutional review board approval at the Massachusetts General Hospital (MGH), we retrospectively reviewed the records of 47 patients with spinal arteriovenous malformations (AVMs) evaluated by spinal angiography between January 2004 and December 2013. Of these lesions, 7 were determined to be paraspinal lesions, 2 were juvenile type lesions, 2 were glomus type lesions, and 2 were perimedullary or Type 4 spinal AVMs. The remaining 34 lesions were sDAVFs or Type I spinal vascular malformations, which were treated with endovascular and/or open surgical modalities. ${ }^{2}$ The study sample was collected by reviewing the MGH cerebrovascular surgery and radiology databases within the study period. All historical, clinical, radiological, and follow-up information was obtained from the electronic medical record in accordance with the Health Insurance Portability and Accountability Act (HIPAA).

Detailed historical, clinical, radiological, and follow-up data were collected for each patient. Recanalization, or recurrence, was defined as the presence of persistent arteriovenous shunting or fistula at the time of the first and/or last angiographic follow-up as compared with the initial posttreatment angiogram. Clinical outcomes consisted of the recorded historical and physical examination components of neurological or neurosurgical follow-up appointments, and examination findings were compared with symptoms at presentation. Symptoms were recorded as improved if the patient experienced improvement or resolution of the presenting symptoms and as unchanged or worsened if no changes were noted. At clinical presentation, patients were initially evaluated with MR angiography (MRA) of the spinal vasculature to determine the presence and anatomical level of the lesion (Fig. 1). Patients subsequently underwent spinal digital subtraction angiography (DSA). At the time of angiography, definitive embolization was attempted with $N$-butyl cyanoacrylate (NBCA; Cordis Microvascular Inc.) or ethylene vinyl alcohol (Onyx, Covidien) if the pathological radicular artery did not provide anterior spinal artery (ASA) supply (Fig. 2). If the ASA supply was noted, the patient was referred for surgical intervention (Fig. 3). If the embolization could not be performed for technical reasons, the patient was also referred for surgery. Surgery consisted of laminectomy at the appropriate spinal level with clipping and disconnection of the fistula (Fig. 4). All patients underwent immediate postoperative DSA or MRA to confirm effective fistula disruption, although 4 patients did not undergo later follow-up imaging.

\section{Statistical Analyses}

Descriptive statistics were calculated for clinical and radiological factors, using the median and/or mean as a measure of central tendency. Fisher's exact test was performed using GraphPad software with $\mathrm{p}<0.05$ prospectively determined as a level of statistical significance.

\section{Results}

\section{Population Characteristics}

A total of 34 patients with sDAVFs were captured in our retrospective search. The characteristic data for these
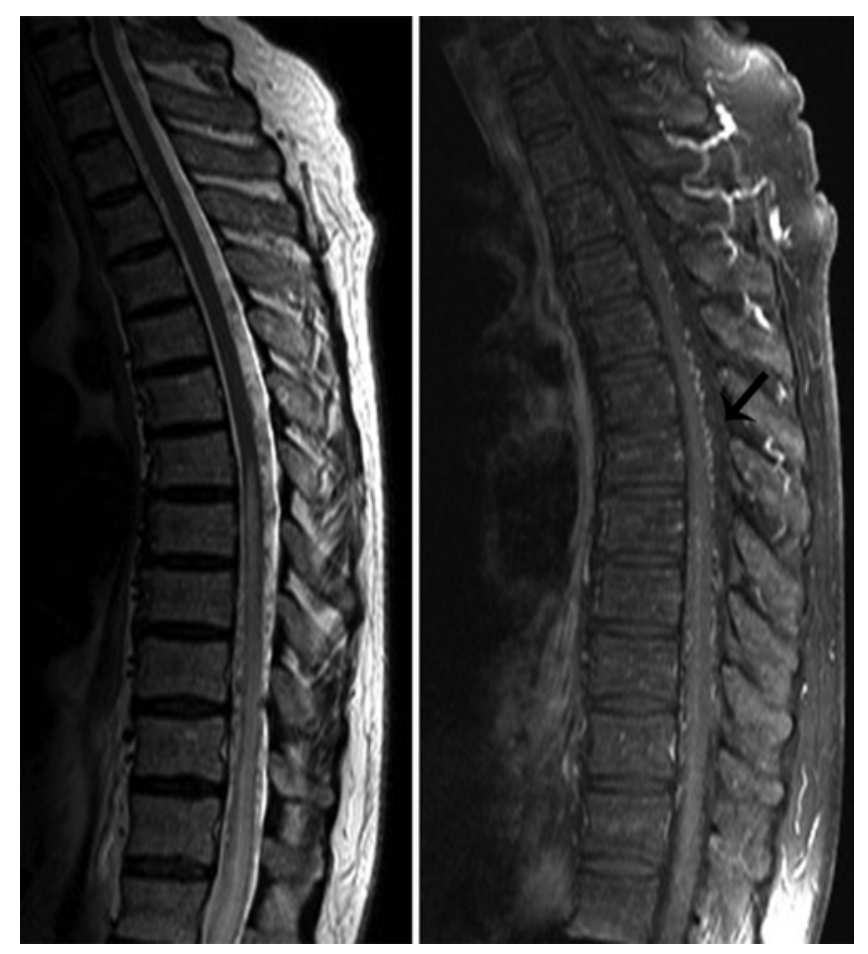

FIG. 1. Sagittal MR images obtained in a patient with a left T-11 sDAVF. Left: T2-weighted image demonstrating typical T2 cord signal abnormality associated with fistulas. Right: T1-weighted image with gadolinium showing serpiginous dorsal spinal vein (arrow).

patients and their pathologies are detailed in Table 1. Twenty-nine of the patients $(85 \%)$ were male, and the median patient age was 63.3 years. No family history of vascular malformations was noted at presentation for any of the patients.

Gait, sensory changes, weakness, and bowel and/or bladder dysfunction were the most frequent chief complaints among the patients (13 [38\%]; Table 1). Only 3 patients presented with a "complete" spinal cord injury with plegia, sensory changes, and loss of sphincter function. As described in prior series, the majority of lesions in this study were located within the thoracic spine (20 [59\%]), followed by the lumbar spine (12 [35\%]). Cervical fistulas were rare $(2[6 \%])$.

All patients underwent spinal DSA following a spinal MRA study suggesting vascular pathology. Endovascular embolization was attempted as the primary treatment for 20 fistulas (59\%). The remaining 14 lesions (41\%) were initially treated with surgery. In those cases in which endovascular intervention was not attempted, ASA feeders were found in proximity to the fistula, precluding a reasonably safe embolization. Ethylene vinyl alcohol was the primary agent used in the majority of embolizations (16 $[80 \%]$ ), and NBCA was used in the remaining $4(20 \%)$.

\section{Outcome Data}

Following treatment, 30 of 34 patients were followed up with DSA and/or MRA over an average of 36 weeks following intervention. Preoperative MRA was accurate with correct laterality and level in 22 patients $(65 \%)$, within 2 levels in 25 patients (74\%), and was indeterminate 


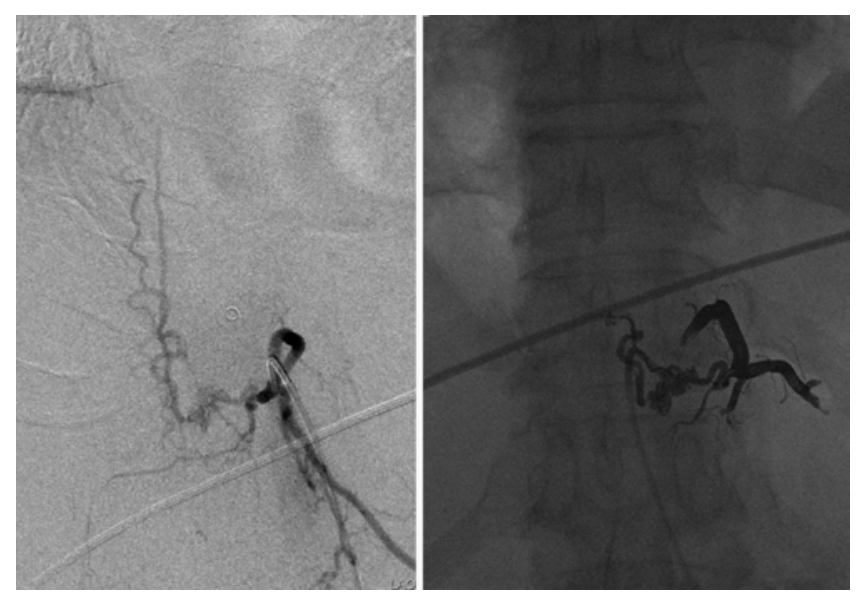

FIG. 2. Intraoperative angiograms obtained in a patient with a left T-11 sDAVF treated with embolization. Left: Segmental vessel angiogram demonstrating fistula opacification. Right: The T-11 segmental vessel with Onyx cast and no persistent sDAVF filling.

in 9 patients (26\%). The median length of stay following treatment was 3.5 days ( 5 days for open procedures, 2 days for endovascular procedures), and the median procedure length was 4 hours ( 5 hours for an open procedure, 3 hours for an endovascular procedure).

Of the 17 patients who underwent endovascular intervention as their primary treatment (Fig. 1) and had follow-up DSA or MRA, 11 (65\%) had complete occlusion at the time of initial treatment. Five of the 6 remaining patients with residual filling at the follow-up angiography were subsequently treated with open surgery. One patient underwent further embolization to attain complete lesion obliteration. The 4 patients treated with NBCA did not show delayed recanalization. Patients treated primarily with open surgical intervention (Fig. 4) had no evidence of persistent arteriovenous shunting at the follow-up (13 patients), although 1 patient required multiple operations within the same hospitalization to effectively address the lesion ( $\mathrm{p}=0.0237$; Table 2).

At the most recent clinical follow-up, 30 patients (88\%) had experienced some resolution of their presenting symptoms: 17 (85\%) of 20 treated with endovascular embolization compared with 13 (93\%) of 14 treated with open surgery $(\mathrm{p}=0.63)$, indicating that there was no associated difference between those patients who underwent primary endovascular treatment and those who underwent primary surgical treatment. Endovascular patients with partial embolization who progressed to further treatment also had symptom improvement; all 6 patients showed partial symptom resolution. Eighteen patients had presented with symptoms progressing over the course of more than 52 weeks, with the other 16 patients presenting with subacute to acute deterioration. No statistically significant association was found between symptom recovery and time to presentation $(\mathrm{p}=1.00)$. Three patients $(2$ treated with open surgery and 1 with endovascular embolization) presented with complete spinal cord injury (American Spinal Injury Association [ASIA] A); 1 of them demonstrated slight recovery (ASIA B) on follow-up.

Complications were observed in 1 patient who had undergone primary surgical intervention; he required repeat

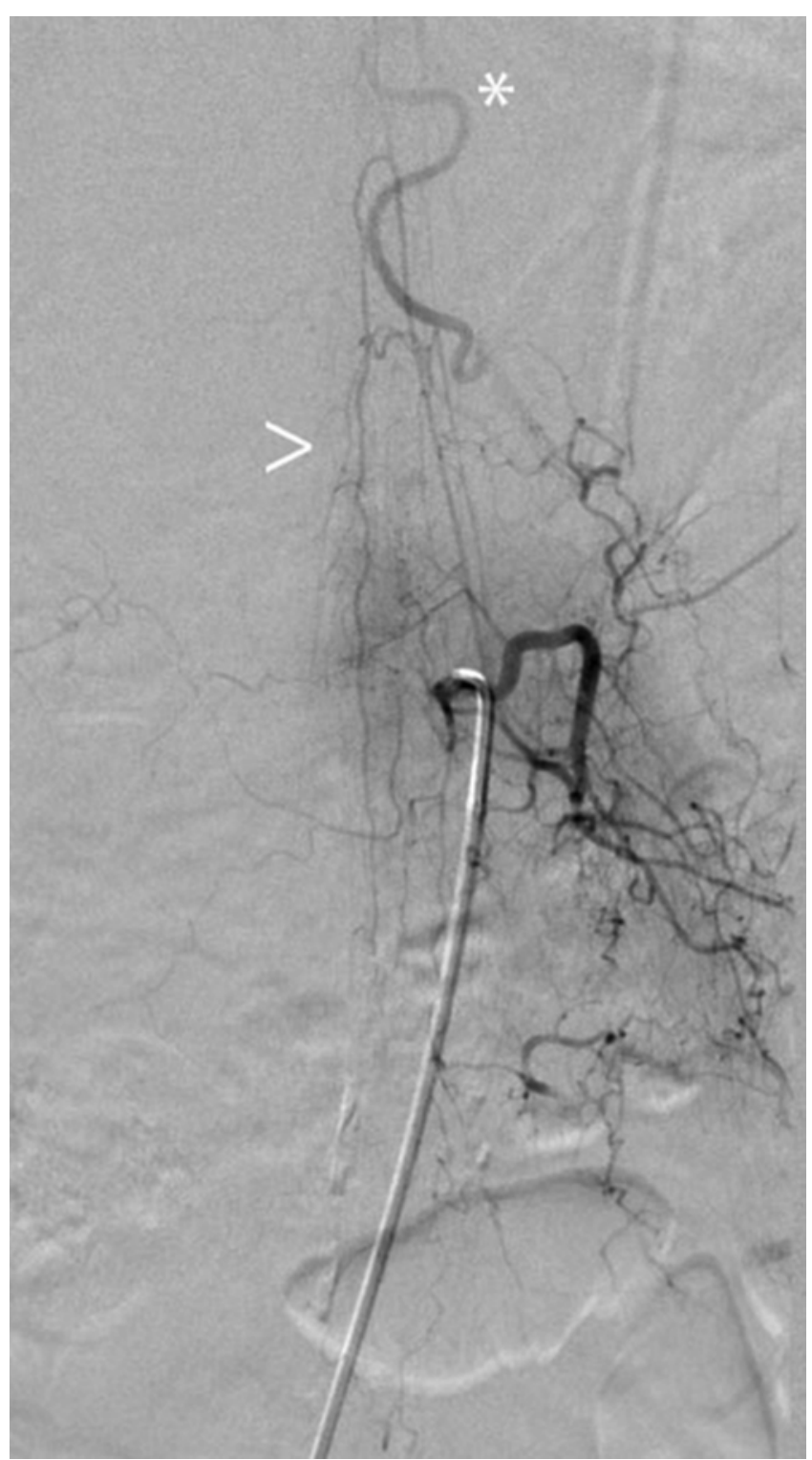

FIG. 3. Spinal digital subtraction angiogram of the left T-11 segmental vessel demonstrating opacification of ASA (arrowhead) and fistula (asterisk).

surgery because of a symptomatic pseudomeningocele following his initial surgery. Another patient required additional follow-up for a wound seroma that was managed conservatively. Among the endovascular cases, 2 microcatheter ruptures occurred during primary embolization. Dissection of a thoracic segmental vessel occurred without vascular compromise and was managed conservatively; it was noted to have resolved at follow-up angiography. Also of note, 10 of the endovascular patients received $>5$ Gy of radiation during the course of their embolization procedure.

\section{Discussion}

Spinal dural arteriovenous fistulas represent the most common form of spinal vascular malformation. ${ }^{4,6,7,9}$ As reflected in our data, they occur more frequently in men and in the thoracic and lumbar spine. Our experience reflects a 

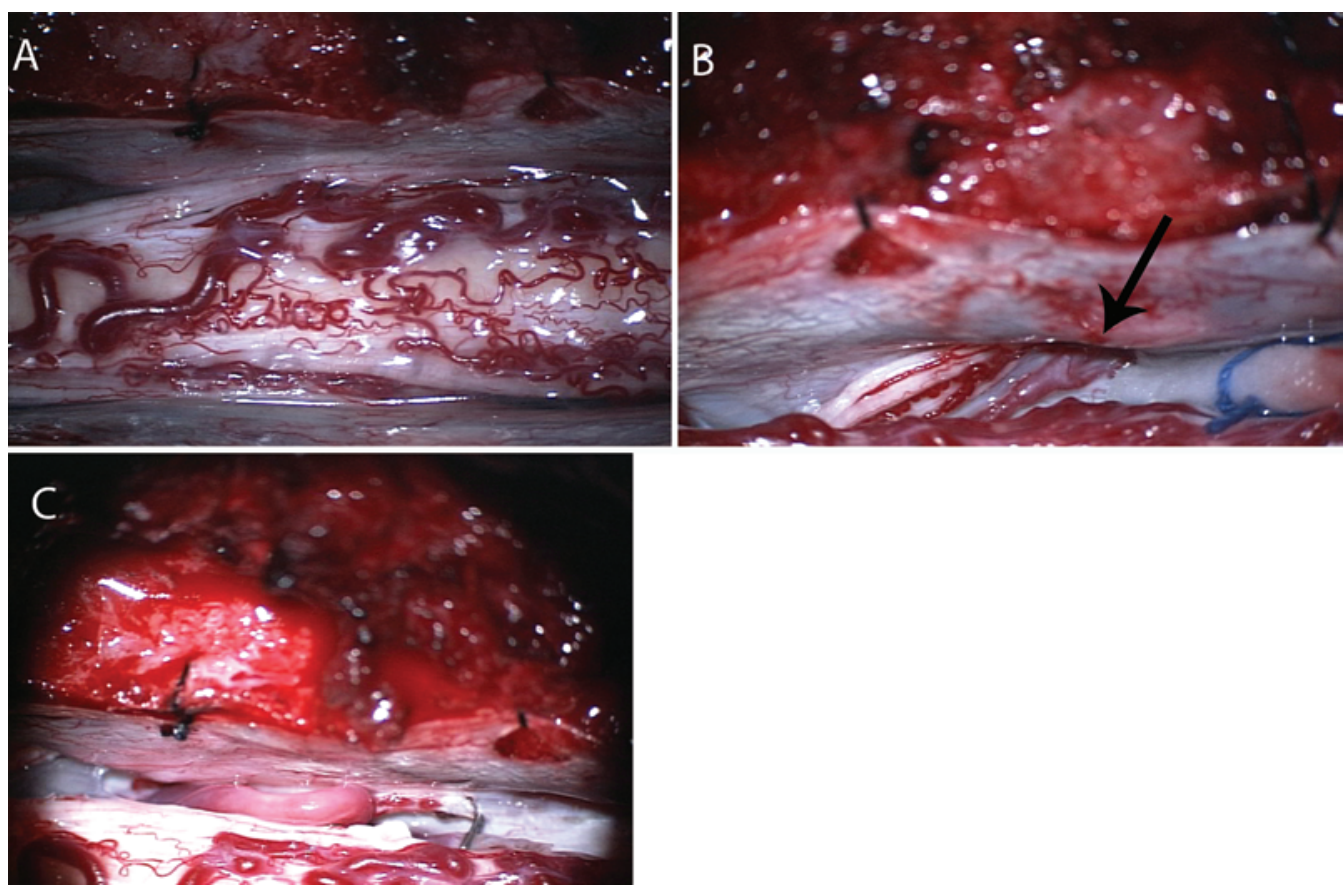

FIG. 4. Intraoperative images obtained in a patient with a right T-11 SDAVF treated with microsurgical ligation. A: The spinal cord with a dorsal arterialized vein. B: The point of a fistula (arrow) between the radicular artery and vein. C: Clip ligation demonstrating obliteration of the fistula. Figure is available in color online only.

growing trend within the endovascular and surgical communities evaluating both interventional and surgical options in planning treatment, with strong consideration given to endovascular treatment if feasible and safe..$^{3,5,12,14,15}$

Surgical occlusion has been the mainstay treatment of these lesions since their recognition given their relatively favorable anatomy and surgical feasibility. Advances in intraoperative microscopy and imaging have augmented our ability to address these lesions surgically. ${ }^{13}$ As seen in our cohort, patients fare very well overall with little surgical morbidity. For example, only 1 surgically addressed case required more than 1 operation to close the lesion. No deterioration reflecting a cord or nerve root injury at the time of surgery was seen in our cohort.

Endovascular intervention has developed from an adjunct to a potential alternative to surgery. ${ }^{1,8,10,11,16,17}$ Improved embolic agents such as ethylene vinyl alcohol copolymer have increased the number of lesions that can be considered for endovascular intervention. Yet, as shown in our results, the efficacy and overall durability of this method remains inferior to surgical occlusion. The complete occlusion in the cases treated with NBCA merits further study, but given our small number of cases, definitive conclusions cannot be drawn. Moreover, the technical limitations of embolic treatment are borne out in our cohort. An ASA originating from the same level as the sDAVF occurred in nearly half of our patients, limiting the generalizability of endovascular embolization to all sDAVFs. Nonetheless, within our cohort, endovascular intervention as a primary treatment was not associated with an overall worse outcome. However, the microcatheter perforations and the $>5$-Gy radiation exposure in 10 patients indicate that we must continue to improve our technologies and techniques to secure these lesions in a shorter period of time with less radiation exposure.
Unfortunately, because of its retrospective nature, our study has many shortcomings that make definitive conclusions difficult. Confounders regarding clinical decision always confuse the strength of the presented conclusions as well as their applicability across different centers. Al-

TABLE 1. Summary of patient and sDAVF characteristics

\begin{tabular}{lc}
\hline \multicolumn{1}{c}{ Characteristic } & Value \\
\hline Total no. of patients & 34 \\
\hline Median age (yrs) & 63.3 \\
\hline Males & 29 \\
\hline Symptoms & 2 \\
\hline Pain & 3 \\
\hline Weakness & 2 \\
\hline Sensation & 10 \\
\hline Weakness \& sensation changes & 13 \\
\hline Gait, sensation changes, weakness, \& sphincteric & 3 \\
\hline dysfunction & 1 \\
\hline Plegia, sensory loss, sphincteric dysfunction & 2 \\
\hline Headache & 20 \\
\hline Location of sDAVF & 12 \\
\hline Cervical & \\
\hline Thoracic & 20 \\
\hline Lumbar & 16 \\
\hline Primary treatment modality & 4 \\
\hline Endovascular embolization & \\
\hline Onyx & \\
\hline NBCA & \\
\hline Open surgery & \\
\hline & \\
\hline
\end{tabular}


TABLE 2. Radiological and clinical outcomes of endovascular and open surgical treatment of sDAVF

\begin{tabular}{|c|c|c|c|c|c|c|}
\hline \multirow[b]{2}{*}{ Treatment } & \multicolumn{2}{|c|}{ Degree of Occlusion* } & \multicolumn{2}{|c|}{ Clinical Symptoms $†$} & \multicolumn{2}{|c|}{ Retreatment $\ddagger$} \\
\hline & Complete & Incomplete & Improvement & No Change or Worsened & Not Required & Required \\
\hline Endovascular & 11 & 6 & 17 & 3 & 11 & 9 \\
\hline Onyx & 7 & 6 & 13 & 3 & 7 & 9 \\
\hline NBCA & 4 & 0 & 4 & 0 & 4 & 0 \\
\hline Open surgery & 13 & 0 & 13 & 1 & 13 & 1 \\
\hline
\end{tabular}

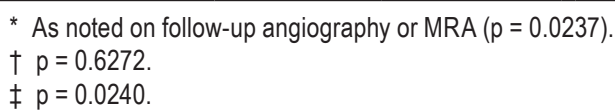

though the need for open surgical treatment after an attempt at embolization can appear as a shortcoming of the endovascular intervention, it can aid anatomical localization in the surgical dissection. Possible benefits of this nature are difficult to parse out. Furthermore, the variability in patient follow-up (both clinical and radiological) and stratified examination of patient outcomes limit the full reliability of the data.

\section{Conclusions}

Open neurosurgical intervention was associated with more frequent occlusion of sDAVFs as well as a decreased need for further procedures. Endovascular intervention as a primary intervention was not associated with worse outcomes but was associated with incomplete fistula occlusion and the need for repeat endovascular and/or surgical procedures. Surgical intervention should continue to be considered as the primary management for sDAVF.

\section{References}

1. Andres RH, Barth A, Guzman R, Remonda L, El-Koussy M, Seiler RW, et al: Endovascular and surgical treatment of spinal dural arteriovenous fistulas. Neuroradiology 50:869876, 2008

2. Anson JA, Spetzler RF: Interventional neuroradiology for spinal pathology. Clin Neurosurg 39:388-417, 1992

3. Bakker NA, Uyttenboogaart M, Luijckx GJ, Eshghi OS, Mazuri A, Metzemaekers JD, et al: Recurrence rates after surgical or endovascular treatment of spinal dural arteriovenous fistulas: a meta-analysis. Neurosurgery 77:137-144, 2015

4. Eskandar EN, Borges LF, Budzik RF Jr, Putman CM, Ogilvy CS: Spinal dural arteriovenous fistulas: experience with endovascular and surgical therapy. J Neurosurg 96 (2 Suppl):162-167, 2002

5. Gemmete JJ, Chaudhary N, Elias AE, Toma AK, Pandey AS, Parker RA, et al: Spinal dural arteriovenous fistulas: clinical experience with endovascular treatment as a primary therapy at 2 academic referral centers. AJNR Am J Neuroradiol 34:1974-1979, 2013

6. Hassler W, Thron A, Grote EH: Hemodynamics of spinal dural arteriovenous fistulas. An intraoperative study. J Neurosurg 70:360-370, 1989

7. Huffmann BC, Gilsbach JM, Thron A: Spinal dural arteriovenous fistulas: a plea for neurosurgical treatment. Acta Neurochir (Wien) 135:44-51, 1995

8. Jellema K, Sluzewski M, van Rooij WJ, Tijssen CC, Beute GN: Embolization of spinal dural arteriovenous fistulas: importance of occlusion of the draining vein. J Neurosurg Spine 2:580-583, 2005

9. Morgan MK, Marsh WR: Management of spinal dural arteriovenous malformations. J Neurosurg 70:832-836, 1989
10. Narvid J, Hetts SW, Larsen D, Neuhaus J, Singh TP, McSwain H, et al: Spinal dural arteriovenous fistulae: clinical features and long-term results. Neurosurgery 62:159-167, 2008

11. Rodesch G, Hurth M, Alvarez H, Tadie M, Lasjaunias P: Spinal cord intradural arteriovenous fistulae: anatomic, clinical, and therapeutic considerations in a series of 32 consecutive patients seen between 1981 and 2000 with emphasis on endovascular therapy. Neurosurgery 57:973-983, 2005

12. Ruiz-Juretschke F, Perez-Calvo JM, Castro E, García-Leal R, Mateo-Sierra O, Fortea F, et al: A single-center, long-term study of spinal dural arteriovenous fistulas with multidisciplinary treatment. J Clin Neurosci 18:1662-1666, 2011

13. Saladino A, Atkinson JL, Rabinstein AA, Piepgras DG, Marsh WR, Krauss WE, et al: Surgical treatment of spinal dural arteriovenous fistulae: a consecutive series of 154 patients. Neurosurgery 67:1350-1358, 2010

14. Sasamori T, Hida K, Yano S, Asano T, Seki T, Houkin K: Long-term outcomes after surgical and endovascular treatment of spinal dural arteriovenous fistulae. Eur Spine J 25:748-754, 2016

15. Schuss P, Daher FH, Greschus S, Vatter H, Güresir E: Surgical treatment of spinal dural arteriovenous fistula: management and long-term outcome in a single-center series. World Neurosurg 83:1002-1005, 2015

16. Steinmetz MP, Chow MM, Krishnaney AA, AndrewsHinders D, Benzel EC, Masaryk TJ, et al: Outcome after the treatment of spinal dural arteriovenous fistulae: a contemporary single-institution series and meta-analysis. Neurosurgery 55:77-88, 2004

17. Van Dijk JM, terBrugge KG, Willinsky RA, Farb RI, Wallace MC: Multidisciplinary management of spinal dural arteriovenous fistulas: clinical presentation and long-term follow-up in 49 patients. Stroke 33:1578-1583, 2002

\section{Disclosures}

Dr. Patel is a consultant for Medtronic-Covidien and Penumbra.

\section{Author Contributions}

Conception and design: Koch, Stapleton, Agarwalla, Patel. Acquisition of data: Koch. Analysis and interpretation of data: Koch. Drafting the article: Koch. Critically revising the article: Koch, Stapleton, Torok, Rabinov, Patel. Reviewed submitted version of manuscript: Koch, Stapleton, Shin, Coumans, Borges, Ogilvy, Rabinov, Patel. Approved the final version of the manuscript on behalf of all authors: Koch.

\section{Correspondence}

Matthew J. Koch, Department of Neurosurgery, Massachusetts General Hospital, 15 Parkman St., ACC-021, Boston, MA 02114. email: mjkoch@mgh.harvard.edu. 